\title{
Unravelling the status of partially identified insect biological control agents introduced to control insects: an analysis of BIOCAT2010
}

\author{
Matthew J. W. Cock
}

Received: 17 September 2018/Accepted: 17 December 2018/Published online: 5 January 2019

(C) The Author(s) 2019

\begin{abstract}
The BIOCAT2010 (corrected) database of introductions of insects used as classical biological control agents (BCAs) against insects was analysed to recognise those introductions which involved a partially identified BCA, e.g. named to genus or family, but not to species. Quality controls made on a selection of these checked whether new taxonomic information in the literature had been missed from the database and this was found to be infrequent. Of $6227 \mathrm{BCA}$ introductions since the 19th century, 686 (11.0\%) were not identified to species level, and 74 were only identified to family or order level. Patterns by taxonomic group and countries making the introductions and the overall trend over time are presented. Since the 1990s, partially identified BCAs have been hardly used. Steps to ensure that partially identified BCAs can be identified in future are set out, and suggestions made regarding the scope for retroactive studies to recognise and name partially identified BCAs.
\end{abstract}

Handling Editor: Dirk Babendreier.

Electronic supplementary material The online version of this article (https://doi.org/10.1007/s10526-018-09921-1) contains supplementary material, which is available to authorized users.

M. J. W. Cock $(\square)$

CABI, Bakeham Lane, Egham TW20 9TY, UK

e-mail: m.cock@cabi.org
Keywords Taxonomy $\cdot$ Vouchers · Identification · DNA barcoding

\section{Introduction}

In the 20th century, the use of partially identified biological control agents, particularly insect biological control agents (BCAs) to control insect pests, was a fairly common occurrence in classical biological control, as shown below. However, the guidelines now in place (e.g. IPPC 2005; Bigler et al. 2005) recommend the use of BCAs with full taxonomic identification, and this is now required by regulatory authorities of many countries. Here, the records in the BIOCAT database of insect BCAs introduced to control insects (Greathead and Greathead 1992; Cock et al. 2016) were analysed to show how the use of partially identified insects BCAs has declined and now has been almost eliminated in the implementation of classical biological control.

The following analysis is based on BIOCAT2010, which includes published information to the end of 2010 (Cock et al. 2016). Several omissions and minor errors have been adjusted (Kenis et al. 2017) and this version is referred to as 'BIOCAT2010.2', which was the starting point for the present analysis. Additional corrections were found to be necessary during quality control checks for the present analysis, resulting in 
'BIOCAT2010.3', which is the version used to present the summary results below. A new version is currently in preparation to bring the database up to date, but this is not yet available. BIOCAT provides a simple record of what insect biological control agents have been introduced where, from where, when, to control what insect pests(s) and with what results. It has been compiled from major global and regional reviews of classical biological control as well as more focussed publications. There are some major gaps in the published data with regard to the scientific names of BCAs used, whether they became established or not, and whether those that became established had any impact or not. This paper focuses on the first of these, i.e., the incomplete identification of BCAs deliberately introduced for classical biological control. Biological control practitioners are invited to check these conclusions, and where possible encouraged to fill some of the gaps.

In updating BIOCAT (Cock et al. 2016), taxonomy of BCAs was based on recent taxonomic catalogues, and this included some cases where introduced BCAs were named after they were introduced as BCAs. For example, introductions against spiralling whitefly, Aleurodicus dispsersus Russell (Hemiptera: Aleyrodidae) in the 1980s and 1990s included a species variously referred to as Encarsia ?haitiensis, Encarsia sp. ?haitiensis, Encarsia sp. poss. haitiensis, Encarsia sp. nr. haitiensis, Encarsia sp. not haitiensis, etc. (Hymenoptera: Aphelinidae). These all refer to the same species, which was described as E. dispersa Polaszek some years after the introductions (Polaszek et al. 2004). In BIOCAT2010.2 all these introductions have been updated as E. dispersa. Examples of this sort will not appear in the following analysis.

Another example of ambiguity was where two or more known species of the same genus were introduced, but appear in the literature under the generic name only. For example, Bracon thurberiphagae (Muesebeck) and B. cajani Muesebeck (Hymenoptera: Braconidae) were introduced into Bahamas for the control of a pigeon pea pod borer, Ancylostomia stercorea (Zeller) (Lepidoptera: Pyralidae), and recorded in BIOCAT as 'Bracon spp.'. In this case, although it was known that it was these two species that were being sent and released, because they were sent as lab-formed cocoons from field collections, the exact count of each BCA was not known and they were reported as Bracon spp. (Cock 1985). These are not technically unidentified BCAs, but will appear as such in this analysis until corrected.

A much more common situation occurred when an introduced BCA was identified to genus only. This might be with or without a qualifying comment regarding the affinities of the species introduced. The case of E. diversa above, where the names used for the Encarsia sp. parasitoid referred to its similarity to E. haitiensis, is a good example of where such comments have facilitated subsequent clarification. If this species had been introduced as simply Encarsia sp., it would have been less obvious that this actually referred to the species subsequently named $E$. diversa.

Our taxonomic understanding changes over time, and BCAs introduced under one name may subsequently be found to be a different species or a mixture of two or more species. Sometimes this is reflected in different geographical or host origins of what appears to be the same species, which subsequently were recognised to be different species. These problems will not be reflected in this analysis since either the name has been simply updated following current taxonomy, or the new name(s) have been added to the literature and hence incorporated into BIOCAT.

Here, the use of partially identified insect BCAs used to control insects is analysed to assess its frequency, which taxonomic groups are involved, and whether the practice has declined over time. This will be the basis for a brief consideration of what should be done to compensate for this practice where it cannot be avoided, and rectify past shortcomings with the benefit of hindsight and new investigations.

\section{Materials and methods}

The BIOCAT2010.2 database, as described in Cock et al. (2016), was used as the information source for this work. BCA names in BIOCAT are characterised by 'BCA order', 'BCA family', 'BCA genus', 'BCA species', and 'BCA notes' (used to record synonyms in the recent literature, subspecies names, or non-specific details such 'sp. nr. haitiensis'). All partially identified BCAs in BIOCAT have the 'BCA species' name as 'sp' or 'spp', and those for which the genus is unknown have the 'BCA genus' as 'Unidentified' and the 'BCA species' name as 'sp' or 'spp'. An analysis was carried out to identify all those species flagged as 'sp' or 'spp' in the 'BCA species' field. 
Two analyses were made to assess whether these records of partially identified BCAs really represent the current state of knowledge when all published accounts are taken into consideration. Since no rigorous or systematic search for taxonomic publications naming or describing previously used BCAs were made when updating BIOCAT2010, it seems likely that species names are now available for some of the BCAs that were introduced without a full species name. To test this, in the first analysis, 27 records of introductions were selected (by sorting the records of partially identified BCAs on 'BCA order', 'BCA family', 'BCA genus', 'release country', and then selecting every 25 th record) and a targeted search of the literature made to look for new information on the identity of the BCAs.

It might be anticipated that BCAs that have been reported as established are unlikely to be partially identified, and in particular none that are credited with making a contribution to the success of a classical biological control programme would remain partially identified. This was checked in the second analysis. Of 691 release records involving partially named BCAs, $16(2 \%)$ were listed in BIOCAT2010.1 as contributing to a substantial or better success. This group was the subject of another targeted search of the literature to look for new information on the identity of the BCA.

Following adjustments arising from these quality control checks, BIOCAT2010.3 was used to summarise the use of partially identified BCAs over time, by impact, and by countries. For the analysis, each introduction of the same BCA species from a different source country is treated as a separate BCA introduction (rather than populations of one BCA species from several countries being treated as one introduction), but 23 introductions of more than one species with the same partial identification (e.g. Encarsia spp.) are each treated as a single introduction. The numbers presented here in Tables 1, 2, 3 and Fig. 1 were generated using standard counting, sorting and table tools.

\section{Results}

Of the 27 selected records examined as to whether new or better information could be located for the identity of the BCA, no further information could be found for 16 (one of which was found to have not been released).
However, supplementary information regarding the possible species involved, or its biology that might help recognise it in the future, were found for ten records, and in one case, reinterpretation of the literature gave species names. The record of Trichogramma spp. (Hymenoptera: Trichogrammatidae) introduced to control potato tuber moth, Phthorimaea operculella (Zeller) (Lepidoptera: Gelechiidae), in Spain in 1944 refers to the two species introduced to control codling moth, Cydia pomonella (Linnaeus) (Lepidoptera: Torticidae), i.e. T. minutum Riley and T. pretiosum Riley (Greathead 1976). Note the latter was considered a synonym of the former at the time Greathead (1976) wrote this, although they are considered separate species now. Hence, Jacas et al. (2006) list both species in their more recent overview of biological control introductions into Spain. Thus, based on this sample, the information in BIOCAT2010 regarding $\mathrm{BCA}$ identities seems to be almost always current.

When the 16 records relating to a substantial success or better were examined (see details in Supplementary Material), no improvement could be found for eight, and supplementary information on related species, source hosts, etc., but not species names were found for two. However, in three cases additional information was located in the source documents which indicated the species released, in two cases publications subsequent to the releases were found that provided a species name, and in one case similar information published since 2010 (the literature cut-off date for the revision of BIOCAT 2010) was found. Thus, in this group of cases, where the partially identified BCAs were considered most likely to have been subsequently named, there were five cases (31\% of the 16 BCAs reported associated with substantial successes) where a name could have been located by careful review of the available literature at the time of the update by Cock et al. (2016). On balance these two tests of data integrity indicated that there was little scope for more complete naming of the majority of introduced BCAs based on published literature. Indeed, in this small sample, it was more likely that information was overlooked in the original publications, than more recent publications attributing names to the successful BCAs were overlooked. The implied level of incomplete information in BIOCAT2010 should be borne in mind when the compilations that follow are examined: the general pattern 
Table 1 Historical totals for the use of partially identified insect biological control agents in classical biological control of insects

\begin{tabular}{lcc}
\hline Introductions & Number of separate BCA introductions & Percentage of total introductions \\
\hline Identified only to order & 28 & 0.4 \\
Identified only to family & 49 & 0.8 \\
Identified only to genus & 543 & 8.7 \\
Identified to genus with a qualifier & 69 & 1.1 \\
Identified to species & 5541 & 89.0 \\
Total introductions & 6227 & 100 \\
\hline
\end{tabular}

Table 2 Breakdown of introductions of partially identified insect BCAs by taxonomic groups

\begin{tabular}{llllll}
\hline Order & $\begin{array}{l}\text { Number of } \\
\text { introductions of } \\
\text { unidentified BCAS }\end{array}$ & Family & $\begin{array}{l}\text { Number of } \\
\text { introductions of } \\
\text { unidentified BCAS }\end{array}$ & Genus & $\begin{array}{l}\text { Number of } \\
\text { introductions of } \\
\text { unidentified BCAS }\end{array}$ \\
\hline $\begin{array}{lllll}\text { Hymenoptera } \\
\text { Coleoptera }\end{array}$ & 485 & Coccinellidae & 102 & Encarsia & 31 \\
Diptera & 41 & Braconidae & 100 & Scymnus & 24 \\
Neuroptera & 11 & Aphelinidae & 83 & Aphytis & 23 \\
Four other & 7 & Encyrtidae & 53 & Eretmocerus & 17 \\
orders & & Ichneumonidae & 47 & Allotropa & 15 \\
& & Eulophidae & 40 & Bracon & 14 \\
& & Platygastridae & 31 & Apanteles & 14 \\
& & Tachinidae & 24 & Hyperaspis & 14 \\
& & Pteromalidae & 22 & Trichogramma & 12 \\
& & Carabidae & 17 & Anagyrus & 11 \\
& & Trichogrammatidae & 17 & Chelonus & 11 \\
& & Bethylidae & 12 & Goniozus & 10 \\
& & 34 other families & 113 & 201 other & 416
\end{tabular}

The sequence of order, family and genus is based on the numbers of partially identified BCA releases of each

will be accurate, but individual numbers may be slightly inaccurate.

A total of 691 release records involving partially named BCAs were located in BIOCAT2010.2. Following the quality checks described above, five records were improved or deleted, leaving 686 records of introductions. This corrected database (BIOCAT2010.3) was used for the remainder of the analysis. Of these 686 introductions, $65(9.5 \%)$ have been reported to be established. Of the 65 established, $17(26.2 \%)$ are reported to have contributed to a partial or better success and $11(16.9 \%)$ to a substantial or better success.
The number of BCA introductions at each level of identification was compiled in Table 1. Of 6227 introductions analysed, $686(11.0 \%)$ were not identified to species level, and 74 (1.2\%) were not identified to genus level (Table 1). The analysis hereafter focusses on these 686 introductions of partially identified BCAs.

Table 2 provides a breakdown of the partially identified introduced BCAs by order, family and genus. Although Hymenoptera are the order most frequently partially identified, the family most frequently partially identified is Coccinellidae. 
Table 3 Insect biological control agents (BCAs) without species level identification released to control insects for those countries that have made more than 50 releases of BCAs

\begin{tabular}{|c|c|c|c|}
\hline Country & $\begin{array}{l}\text { Number of partially identified BCA } \\
\text { releases }\end{array}$ & $\begin{array}{l}\text { Total number of BCA } \\
\text { releases }\end{array}$ & $\begin{array}{l}\text { Percentage of releases that were partially } \\
\text { named }\end{array}$ \\
\hline Australia $^{a}$ & 72 & 343 & 21.0 \\
\hline Barbados & 17 & 87 & 19.5 \\
\hline Fiji & 20 & 137 & 14.6 \\
\hline $\mathrm{USA}^{\mathrm{a}}$ & 274 & 1970 & 13.9 \\
\hline Kenya & 8 & 58 & 13.8 \\
\hline New Zealand & 29 & 212 & 13.7 \\
\hline United Kingdom $^{\mathrm{a}}$ & 30 & 240 & 12.5 \\
\hline Israel & 14 & 127 & 11.0 \\
\hline Mexico & 7 & 71 & 9.9 \\
\hline Peru & 5 & 51 & 9.8 \\
\hline Mauritius & 11 & 142 & 7.7 \\
\hline India & 8 & 110 & 7.3 \\
\hline Canada & 21 & 304 & 6.9 \\
\hline $\begin{array}{l}\text { Trinidad and } \\
\text { Tobago }\end{array}$ & 5 & 78 & 6.4 \\
\hline Italy & 6 & 110 & 5.5 \\
\hline South Africa & 5 & 126 & 4.0 \\
\hline Former USSR & 3 & 82 & 3.7 \\
\hline France $^{a}$ & 3 & 136 & 2.2 \\
\hline Chile & 2 & 95 & 2.1 \\
\hline Philippines & 1 & 57 & 1.8 \\
\hline Spain & 0 & 53 & 0.0 \\
\hline
\end{tabular}

The countries are in sequence by the percentage of such releases

${ }^{\text {a } I n c l u d i n g ~ d e p e n d e n t / t r u s t / o v e r s e a s ~ t e r r i t o r i e s ~}$

In Table 3 the number of releases of partially identified insect BCAs are tabulated for each country that has made more than $50 \mathrm{BCA}$ introductions in total. In general the more BCA introductions a country has made, the larger the number of releases involve partially identified BCAs. However, the percentage of $\mathrm{BCA}$ releases that are partially identified varies greatly between countries, from $0 \%$ to more than $20 \%$.

My starting hypothesis is that the frequency with which partially identified BCAs have been used has gone down over time. The dates of introduction for the 686 partially identified introductions were classified by decade of first introduction (Fig. 1). The proportion of partially identified BCAs used declined only slowly from a peak in the 1950s, but declined substantially in the 2000s, and is now a rare event, with only two examples located from this period. Pseudaphycus sp.
(Hymenoptera: Encyrtidae) was introduced from Mexico into Florida, USA for the control of Paracoccus marginatus (Hemiptera: Pseudococcidae) in 2000 (Meyerdirk et al. 2004; Amarasekare et al. 2010; Mani et al. 2012) and Allotropa sp. nr. mecrida (Hymenoptera: Platygastridae) was introduced from Egypt into the USA for the control of Maconellicoccus hirsutus (Hemiptera: Pseudococcidae) in 2003 (Roltsch et al. 2006).

\section{Discussion}

Partially identified BCAs have been a significant feature in the use of insect BCAs for classical biological control, accounting for $11.0 \%$ of all introductions. This situation has significantly improved 


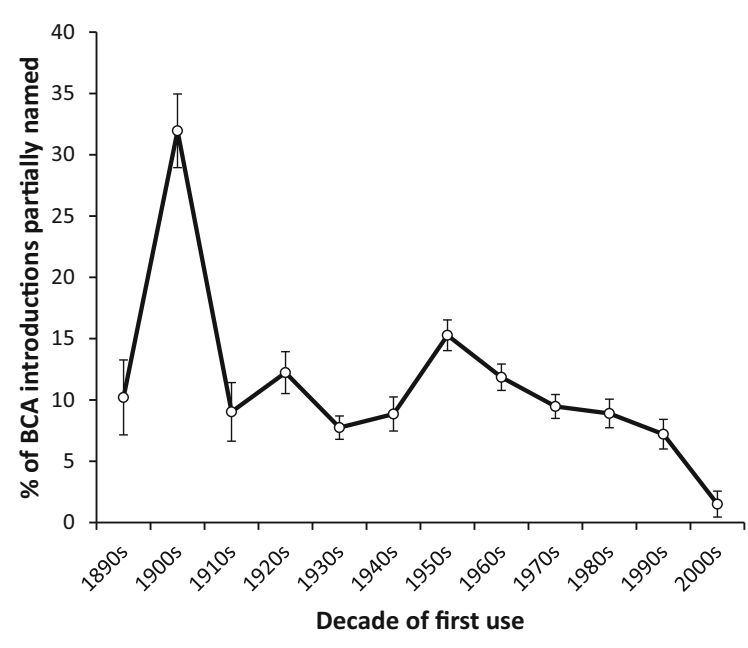

Fig. 1 The percentage of insect classical biological control releases each decade in which the biological control agent was partially named (with SE). The date of release was not available for 38 out of 686 such releases $(5.5 \%)$

since the beginning of the 21 st century. I believe this is a reflection of the increased recognition of the importance of taxonomy in classical biological control, the continuing strong focus of some taxonomists on insect groups used as BCAs, and national regulatory authorities requiring candidate BCAs to be named to species level following international standards such as IPPC (1996, 2005) or Bigler et al. (2005).

Looking to the future, the only reason for using a partially named BCA should be the taxonomic impediment, i.e. there are currently no taxonomists dealing with this group who can name the species. This is a real possibility and may well become more likely as the current trend in the loss of taxonomists dealing with morphological characters and species descriptions continues. Nevertheless, BCAs proposed for introduction need to be characterised and documented so that they can be named in the future, and they can be recognised for what they are in follow up studies for establishment, impact assessment and possible non-target effects. This means following good practice for all BCAs proposed for introduction, i.e. (1) reporting details of where and how the BCA was collected, its biology and diagnostic features, and (2) depositing voucher material in appropriate museum collections in the source and target countries. To this I would add (3) DNA barcoding (Hebert et al. 2003) representative samples of the material imported and the material released, and making these public. If these procedures are followed, there should be no reason for BCAs used today not to be named in the future. For those in a position to do so, it would be worthwhile to obtain whole genome information of the material collected and the material released. Where practical, material for future genetic analysis may be placed in long-term storage, e.g. in liquid nitrogen. Furthermore, genetic sequence data could be used to evaluate how BCA populations change going through the bottleneck of culture and release, and provide reference material to evaluate how BCA populations change during and after establishment.

Historically, the frequency with which partially named species have been used has been fairly constant as a whole over time up to the 1990s (Fig. 1), but the variability between countries is high (Table 3 ). This should be seen as a mandate for further investigation. In many cases there is scope for retroactive evaluation and hypothesis testing regarding the partially named BCAs introduced. Investigators can check local literature and unpublished reports, look for voucher specimens in likely collections, consult taxonomists, and make field collections. If a partially named BCA is reported as established (or establishment is unknown), make surveys in the source area and area of introduction to try and locate fresh material that matches what is known of the BCA, and name/document these. There is a need for national teams and international collaboration to do this. In the process, it is almost certain that new insights will be obtained for old problems: new information will be generated on the pest and whether improved biological control is needed, and field work will generate ideas about the scope for further biological control options where it is still needed. Certainly, many of the old badly documented introductions will not be resolvable, e.g. records of introductions of 'mixed coccinellids' from the early days, but many could be, e.g. 'a couple of hundred' of 'a very slender pale parasitoid' released in one of the leading biological control countries in the 1960s.

In conclusion, partially identified BCAs are scarcely an issue these days, and the procedures and methods exist to maximise the probability that these can be named in the future. The inputs of taxonomists will continue to be essential, and the ongoing decline in taxonomists for key BCA groups is a cause for concern. It should be possible to revisit some of the older biological control programmes and fill some of 
the gaps in the record, and this should improve not only the record of what has been introduced, and what has worked and not worked, but also give new insight into old and often continuing problems.

Acknowledgements I thank Barbara Barrett (AgResearch Invermay, New Zealand), Jim O'Hara (Agriculture and AgriFood Canada), John Noyes and Andrew Polaszek (The Natural History Museum, London) and Don Sands (CSIRO retired) who responded to requests for information regarding particular releases, Ulli Kuhlmann (CABI) for helpful comments, and Peter Cock and colleagues at the James Hutton Institute for their insight on how to store insect BCA material for future genome analysis. I acknowledge with thanks the support of the CABI Development Fund. CABI is an international intergovernmental organisation and I gratefully acknowledge the core financial support from our member countries (and lead agencies) including the United Kingdom (Department for International Development), China (Chinese Ministry of Agriculture), Australia (Australian Centre for International Agricultural Research), Canada (Agriculture and Agri-Food Canada), Netherlands (Directorate-General for International Cooperation), and Switzerland (Swiss Agency for Development and Cooperation). See https://www.cabi.org/ about-cabi/who-we-work-with/key-donors/ for details.

Open Access This article is distributed under the terms of the Creative Commons Attribution 4.0 International License (http:// creativecommons.org/licenses/by/4.0/), which permits unrestricted use, distribution, and reproduction in any medium, provided you give appropriate credit to the original author(s) and the source, provide a link to the Creative Commons license, and indicate if changes were made.

\section{References}

Amarasekare KG, Mannion CM, Epsky ND (2010) Host instar susceptibility and selection and interspecific competition of three introduced parasitoids of the mealybug Paracoccus marginatus (Hemiptera: Pseudococcidae). Environ Entomol 39:1506-1512

Bigler F, Bale JS, Cock MJW, Dreyer H, Greatrex R, Kuhlmann U, Loomans AJM, van Lenteren JC (2005) Guidelines on information requirements for import and release of invertebrate biological control agents in European countries. CAB Rev: Perspect Agric Vet Scie Nut Nat Resour 1(1):1-10

Cock MJW (1985) A review of biological control of pests in the Commonwealth Caribbean and Bermuda up to 1982. Commonwealth Agricultural Bureaux, Farnham Royal
Cock MJW, Murphy ST, Kairo MTK, Thompson E, Murphy RJ, Francis AW (2016) Trends in the classical biological control of insect pests by insects: an update of the BIOCAT database. BioControl 61:349-363

Greathead DJ (1976) A review of biological control in western and southern Europe. Commonwealth Agricultural Bureaux, Farnham Royal

Greathead DJ, Greathead AH (1992) Biological control of insect pests by insect parasitoids and predators: the BIOCAT database. Biocontrol News Inf 13:61N-67N

Hebert PDN, Cywinska A, Ball SL, Dewaard JR (2003) Biological identifications through DNA barcodes. Proc Royal Soc (Lond) Ser B Biol Sci 270:313-321

IPPC (International Plant Protection Convention) (1996) Code of conduct for the import and release of exotic biological control agents. International standards for phytosanitary measures No. 3. Food and Agriculture Organization of the United Nations, Rome

IPPC (International Plant Protection Convention) (2005) Guidelines for the export, shipment, import and release of biological control agents and other beneficial organisms. International standards for phytosanitary measures No. 3 . Food and Agriculture Organization of the United Nations, Rome

Jacas JA, Urbaneja A, Viñuela E (2006) History and future of introduction of exotic arthropod biological control agents in Spain: a dilemma? BioControl 51:1-30

Kenis M, Hurley BP, Hajek AE, Cock MJW (2017) Classical biological control against insect pests of trees: facts and figures. Biol Invasions 19:3401-3417

Mani M, Shivaraju C, Shylesha AN (2012) Paracoccus marginatus, an invasive mealybug of papaya and its biological control-an overview. J Biol Control 26:201-216

Meyerdirk DE, Muniappan R, Warkentin R, Bamba J, Reddy GVP (2004) Biological control of the papaya mealybug, Paracoccus marginatus (Hemiptera: Pseudococcidae) in Guam. Plant Prot Quart 19:110-114

Polaszek A, Manzari S, Quicke DLJ (2004) Morphological and molecular taxonomic analysis of the Encarsia meritoria species-complex (Hymenoptera, Aphelinidae), parasitoids of whiteflies (Hemiptera, Aleyrodidae) of economic importance. Zool Scripta 33:403-421

Roltsch WJ, Meyerdirk DE, Warkentin R, Andress ER, Carrera K (2006) Classical biological control of the pink hibiscus mealybug, Maconellicoccus hirsutus (Green), in southern California. Biol Control 37:155-166

Matthew J. W. Cock is CABI's chief scientist and an honorary member of the International Organization for Biological Control. 